Pecvnia, 8 (2009), pp. 183-201

\title{
Os activos intangíveis nas contas das empresas do PSI 20: uma evidência empírica
}

Recibido: Enero 2009

Aceptado: Septiembre 2009

\author{
Maria da Conceição da Costa Marques \\ mmarques@iscac.pt \\ Inst. Sup. de Contabilidade e \\ Administração de Coimbra \\ Quinta Agrícola - Bancanta \\ 3000 Coimbra (Portugal)
}

En la actualidad podemos enumerar como activos intangibles contables las patentes, marcas, derechos de autor, etc. Sin embargo, hay otros cuya existencia se reconoce ampliamente y que, a pesar de no estar identificados o medidos, también contribuyen a los resultados de una entidad, como el goodwill o el capital intelectual, entre otros.

La Contabilidad de activos intangibles ha cobrado impulso en las últimas décadas debido a los cambios que se han producido en el mundo de los negocios. Los avances en la industria y, en concreto la sociedad de la información, disponen de activos intangibles que son de aplicación en el mundo de los negocios.

El reconocimiento de los activos intangibles en los libros de las entidades puede ser el siguiente paso, en concreto en lo que se refiere a ciertos tipos de negocios, como el de la industria del
Today, as intangible assets recognized by the accounting, we can list the patents, trademarks, copyrights, etc. But there are other intangible assets whose existence is widely acknowledged that although they have not yet been identified or measured, also contribute to the results of an entity such as Goodwill or the Intellectual Capital, among others.

Accounting for intangible assets gained prominence in the past decades due to changes that are occurring in the business world. The industrial revolution and, in particular, the information society, have the resources in front of the intangible world of business.

The recognition of intangible assets on the books of the entities can be the next step forward especially for certain types of business such as the industry of knowledge. 
conocimiento.

En el presente estudio se analizan los factores que influyen en la divulgación e información de activos intangibles voluntarios y obligatorios de un número de empresas portuguesas que cotizan en bolsa. Asimismo, exploramos la línea de pensamiento actual sobre activos intangibles $y$ cómo se evalúan, reconocen y presentan estos recursos en los estados financieros de las empresas portuguesas.

Palabras clave: activos intangibles, Bolsa, capital intelectual.
In this study we analyze the factors influencing the disclosure and information, mandatory and voluntary (intangible assets), of a number of Portuguese companies whose securities are traded on stock exchange. We also explore the current state of thinking on intangible assets and how those resources are being evaluated, recognized and presented in financial statements of Portuguese companies.

Key words: intangible assets, stock exchange, intellectual capital.

\section{INTRODUÇÃO}

O objectivo principal deste trabalho de investigação consiste em efectuar o estudo dos activos intangíveis e analisar algumas questões inerentes à sua identificação, medição, valoração e reconhecimento nas Demonstrações Financeiras. Ao nível empírico, os dados que analisaremos são os de algumas empresas do PSI 20 ${ }^{1}$, constantes das contas de 2007.

Nos últimos anos, a contabilidade dos activos intangíveis converteu-se num problema crescente com o qual se têm debatido os profissionais da contabilidade em todo o mundo. Veja-se a propósito o caso das marcas, a satisfação dos clientes, entre outros (Serrano y Chaparro 2001).

De acordo com Pucich et al. (2001), actualmente surgiram necessidades de informação que não se resolvem com as demonstrações financeiras tradicionais. É o caso do risco a que a empresa está sujeita, os recursos humanos e intelectuais, o impacto ambiental das suas actividades e a impressão dos clientes sobre a qualidade dos produtos que oferece ao mercado. Por outro lado, certos recursos de natureza intangível, são os que geram maior volume de receitas para a organização, visto que os recursos estratégicos já não são os recursos físicos, mas sim as ideias e o conhecimento que se formam na mente da equipa que trabalha em determinada organização.

O PSI20 é o Portuguese Stock Index, ou seja, o principal índice de referência do mercado de capitais português. 
Os administradores das empresas sempre geriram os recursos intangíveis; isso não constitui nada de novo. 0 que é de facto novo, é a intenção de os ponderar e registar contabilisticamente. Poderá dizer-se que para o administrador é mais difícil medi-los e contabilizá-los do que trabalhar com eles.

Uma limitação que o sistema contabilístico actual tem diante de si, é que captura e processa dados essencialmente relacionados com transacções e factos que afectam o património da organização, mas com os recursos do conhecimento, o valor cria-se ou destrói-se sem que exista pelo meio alguma transacção.

São questões como estas que iremos debater no presente artigo, bem como traçar uma perspectiva sobre o que as empresas portuguesas do PSI 20 incluem nas suas demonstrações financeiras.

\section{OS ACTIVOS INTANGÍVEIS}

0 processo de aprendizagem na organização tem em consideração os recursos e capacidades necessários para o desenvolvimento do projecto empresarial. Tal enfoque delimita claramente o papel protagonista das atitudes, aptidões e capacidades adstritas a um exercício empreendedor.

De acordo com Bueno Campos (2007: 38), surge assim a relevância actual da cadeia "informação -conhecimento- inovação" (conforme Figura 1), que reflecte a importância dos activos intangíveis, fruto da passagem da sociedade industrial à sociedade cognitiva, em que o conhecimento é um recurso crítico. Na referida cadeia, a aprendizagem é um veículo fundamental, estruturando assim a capacidade de absorção (autor citado).

$\mathrm{Na}$ actualidade, o valor das empresas, seja no sector industrial, comercial ou de serviços, não reside unicamente nas suas instalações, maquinaria ou edifícios, mas também em aspectos imateriais, tais como a sua capacidade de estabelecer relações estáveis com os seus clientes e conseguir a sua fidelização, a sua capacidade de inovar e introduzir novos produtos ou serviços no mercado, ou a competência técnica e motivação do seu pessoal. Pode assim dizer-se que o valor das empresas na actualidade é dado pelo conjunto dos seus activos tangíveis e intangíveis. Segundo Gutiérrez (2004: 8), nos últimos anos surgiram diversas definições e 
classificações de activos intangíveis com o objectivo de oferecer uma melhor compreensão do conceito, conseguir uma valorização fiel dos investimentos nestes activos e promover a comunicação entre investigadores, dirigentes de empresas, utilizadores da informação financeira e organismos emissores de normas contabilísticas.

Figura 1: As bases da regeneração empresarial

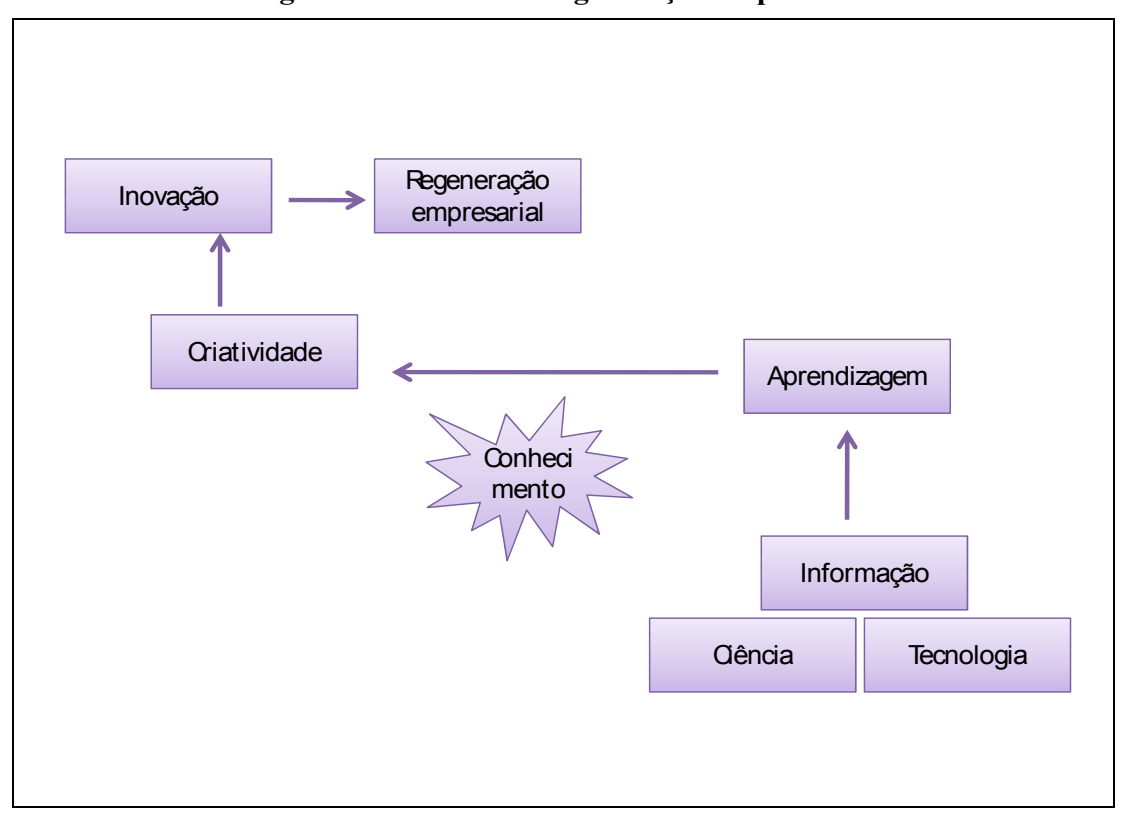

Fonte: Bueno Campos (2007: 38)

Um activo, segundo o IASB - International Accounting Standards Board, é "um recurso, controlado pela empresa, como resultado de acontecimentos passados e do qual se espera que fluam para a mesma benefícios económicos futuros".

De acordo com a Norma Internacional de Contabilidade $\mathrm{n}^{\circ}$ 8, do IASB, um activo intangível é "um activo não monetário identificável sem substância física". O seu reconhecimento na contabilidade exige que a entidade demonstre que esse item satisfaz: (a) a definição de um activo intangível; e (b) os critérios de reconhecimento.

Esta condição aplica-se aos custos incorridos inicialmente para adquirir ou gerar internamente um activo intangível e aqueles incorridos posteriormente para adicionar, substituir parte ou dar assistência ao mesmo. 
Um activo satisfaz o critério da identificabilidade na definição de um activo intangível quando: (a) for separável, ou seja, capaz de ser separado ou dividido da entidade e vendido, transferido, licenciado, alugado ou trocado, seja individualmente ou em conjunto com um contrato, activo ou passivo relacionado; ou (b) resultar de direitos contratuais ou de outros direitos legais, quer esses direitos sejam transferíveis quer sejam separáveis da entidade ou de outros direitos e obrigações.

Um activo intangível só deve ser reconhecido quando: (a) for provável que os benefícios económicos futuros esperados que sejam atribuíveis ao activo fluam para a entidade; e (b) o custo do activo possa ser mensurado fiavelmente.

O critério de reconhecimento de probabilidade é sempre considerado como estando satisfeito relativamente a activos intangíveis que sejam adquiridos separadamente ou numa concentração de actividades empresariais. Inicialmente, um activo intangível deve ser mensurado pelo seu custo.

Gutiérrez (2004: 8), citando Navas y Guerras (1998), defende que as características básicas dos activos intangíveis são as seguintes:

- São activos que se sustentam em informação;

- Esta informação nem sempre é codificável;

- Os direitos de propriedade destes recursos nem sempre estão bem definidos.

Dentro deste tipo de recursos, podem distinguir-se os recursos intangíveis humanos, na medida em que estejam vinculados ao factor humano que faz parte da organização, e os recursos intangíveis não humanos.

\section{IDENTIFICAÇÃO E MEDIÇÃO DOS ACTIVOS INTANGÍVEIS}

\subsection{Definição e classificação de capital intelectual}

Presentemente, numa sociedade que assenta no conhecimento e considerando os activos disponíveis de uma organização, o capital intelectual tem surgido no centro de estudo e de análise, pelo que têm sido por diversos autores apresentadas definições de capital intelectual. 
Stewart (1998: 9) define capital intelectual como conhecimento, informação, propriedade intelectual, experiência, material intelectual, que podem ser utilizados para criar riqueza. Pode entenderse como uma força cerebral colectiva. Estamos perante um conceito difícil de identificar e ainda mais difícil de distribuir de modo eficaz. Porém, quem o encontra e explora, vence. Este autor divide o capital intelectual em três grupos:

i. Capital humano

ii. Capital estrutural

iii. Capital cliente

Edvisson e Malone (1998) usam uma metáfora para explicar o conceito de capital intelectual; comparam a empresa a uma árvore, considerando a parte visível como o tronco, os galhos e as folhas a que está expressa em organigramas, nas demonstrações financeiras e noutros documentos. As raízes, sendo o que está debaixo da superfície, representam o valor oculto, nem sempre relatado pela contabilidade.

Para estes autores existem factores dinâmicos ocultos que alicerçam a empresa, cuja parte visível são os produtos e os edifícios. Esses factores ocultos são:

- Capital Humano - conhecimento, experiência, poder de inovação, habilidades e competências dos empregados. Inclui também os valores, a cultura e a filosofia da empresa.

- Capital Estrutural - os sistemas de informação, o software, os bancos de dados as patentes, as marcas registadas e todo o resto da capacidade organizacional que apoia a produtividade do capital humano.

De acordo com Brooking (1996), citada por Navaza e Cabarcos (2007: 57) o capital intelectual não é nada de novo, tem estado presente desde que o primeiro vendedor estabeleceu uma boa relação com um cliente. Contudo, nas últimas décadas houve um desenvolvimento de determinadas áreas técnicas chave, como os 'media' e comunicação, as tecnologias da informação, que propiciaram novas ferramentas e conduziram à economia global. Muitos destes instrumentos oferecem benefícios intangíveis para as empresas e a sua propriedade proporciona vantagens competitivas e, consequentemente, constituem um activo. 
Para Brooking (1996), o capital intelectual é definido como uma combinação de activos intangíveis que capacitam o funcionamento da empresa.

$$
\text { Empresa }=\text { Activos Materiais }+ \text { Capital Intelectual }
$$

Divide o capital intelectual em quatro categorias:

- Activos de mercado - potencial que a empresa possui derivado dos intangíveis relacionados com o mercado (marcas, clientes e a sua lealdade, negócios recorrentes, negócios em andamento, canais de distribuição, franquias, etc.);

- Activos centrados no indivíduo - benefícios que o indivíduo tende a proporcionar às organizações através do seu conhecimento, criatividade, habilidade para resolver problemas, liderança, capacidade empresarial e de gestão (neste caso relativa aos empresários);

- Activos de propriedade intelectual - activos que necessitam de protecção legal para proporcionarem benefícios à organização (know-how, segredos industriais, copyright, patentes, e marcas de produção e de serviços);

- Activos de infra-estrutura - englobam as tecnologias, as metodologias e os processos utilizados como: cultura, sistemas de informação, métodos de gestão, base de dados de clientes, etc.

0 interesse do capital intelectual é justificado pelas alterações que ocorrem na economia. Há alguns anos atrás, a avaliação da competitividade de uma empresa era realizada em termos de activos tangíveis, existindo uma mão-de-obra relativamente barata, sendo os trabalhadores na maior parte dos casos facilmente substituíveis. Os trabalhadores com pouca formação, não eram considerados por terem conhecimentos úteis, mas como uma ferramenta do processo produtivo.

As empresas de serviços vão precisar, cada vez mais, de infra-estruturas mínimas, onde a tecnologia informática esteja presente. As pessoas precisam de conhecimentos técnicos adequados, que cada vez mais se revelam imprescindíveis. 0 uso de sistemas de informação e a aplicação dos conhecimentos dos trabalhadores permitem a prestação do serviço. 
O capital intelectual, segundo Euroforum (1998), é definido como o conjunto de activos intangíveis de uma organização que apesar de não estarem reflectidos na contabilidade tradicional, geram valor ou têm potencial de o gerar no futuro. Segundo Marques (2005: 5), citando Euroforum (1998), o capital intelectual decompõe-se em:

- Capital humano - corresponde ao conhecimento que as pessoas possuem e é útil para a organização, assim como a capacidade que as pessoas têm de produzir o conhecimento, isto é, a sua capacidade para aprender;

- Capital estrutural - corresponde ao conjunto de conhecimentos que a empresa detém e que fica na organização quando as pessoas saem, porque é independente das mesmas, como por exemplo: a propriedade intelectual, a cultura organizacional, as tecnologias do processo e produto, etc.;

- Capital relacional - corresponde ao conjunto de relações que a empresa mantém com o exterior ou com os agentes internos. Podem ser considerados, entre outros, a satisfação dos clientes e a sua lealdade, a notoriedade da marca, a reputação da empresa, assim como as relações com os fornecedores.

O capital intelectual é definido como um conjunto de activos intangíveis. Almeida (2003: 13) argumenta nesse sentido:
vários autores assimilam a expressão "activos intangíveis" a outras designações. Para além da equivalência já referenciada de Edvinsson e Malone (1999) à expressão "activos ocultos", Lev (2000), por seu turno, referencia os termos "knowledge assets" (activos do conhecimento), utilizado sobretudo por economistas, "intellectual capital" (capital intelectual), ao qual recorrem as literaturas juridica e de gestão, ou mesmo apenas "intangibles" (intangíveis), no jargão contabilístico. Esta equivalência revela um dos elementos essenciais dos activos intangíveis: A sua íntima ligação ao uso do intelecto, materializado através do conhecimento.

De acordo com Navaza e Cabarcos (2007: 27), as várias definições de capital intelectual são coincidentes, pelo que se poderá definir capital intelectual como "o conjunto de recursos intangíveis da empresa num determinado momento". Os conceitos de conhecimento e capital intelectual estão relacionados entre si, já que este último é constituído por todo o conhecimento que produz valor, isto é, todo o 
conhecimento que pode ser transformado em lucros. Deste modo, não se pode considerar todo o conhecimento como capital intelectual, mas todo o capital intelectual é resultado, de forma directa ou indirecta, do conhecimento.

Os activos intangíveis não têm presença física, não se podem ver nem tocar, no entanto há a possibilidade de serem identificados $\mathrm{e}$ adequadamente classificados, de acordo com o quadro abaixo:

\begin{tabular}{|c|c|c|c|}
\hline \multirow[b]{2}{*}{$\begin{array}{c}\text { Património } \\
\text { (Valor da } \\
\text { Contabilidade) } \\
\text { Activos tangíveis } \\
\text { menos as dívidas }\end{array}$} & \multicolumn{3}{|c|}{ Activos Intangíveis } \\
\hline & $\begin{array}{c}\text { Estrutura } \\
\text { externa } \\
\text { (Marcas, clientes } \\
\text { e relações com } \\
\text { fornecedores) }\end{array}$ & $\begin{array}{c}\text { Estrutura } \\
\text { Interna } \\
\text { (Empresa: gestão, } \\
\text { estrutura legal, } \\
\text { sistemas, manuais, } \\
\text { patentes de I\&D, } \\
\text { Software) }\end{array}$ & $\begin{array}{l}\text { Competência } \\
\text { Individual } \\
\text { (Know how, } \\
\text { conhecimentos, } \\
\text { habilidades, } \\
\text { educação, } \\
\text { experiência) }\end{array}$ \\
\hline
\end{tabular}

Fonte: Marques (2005: 4), adaptado de Viedma (2003); Medrano Chivite et al. (2003).

Segundo os autores os activos intangíveis podem ser classificados em:

- Activos de competência individual - estes activos referem-se aos conhecimentos, educação, experiência, Know How e habilidades das pessoas que trabalham numa organização. Este conjunto de activos também denominado por capital humano não é propriedade da organização.

- Activos de estrutura interna - estes activos referem-se à gestão e sistemas de direcção, à cultura da organização, aos métodos e procedimentos de trabalho, ao software, às bases de dados e à investigação e desenvolvimento (I\&D). Este conjunto de activos é da propriedade da organização, podendo alguns deles ser objecto de protecção legal, tais como: patentes, propriedade intelectual, etc.

- Activos de estrutura externa - estes activos referem-se às relações com fornecedores, carteira de clientes, acordos de cooperação e alianças tecnológicas. Este conjunto de activos é da propriedade da organização e podem ser protegidos legalmente, por exemplo: as marcas comerciais. 


\subsection{Importância da medição do capital intelectual}

$\mathrm{Na}$ opinião de Navaza e Cabarcos (2007: 25), o capital intelectual existiu sempre nas empresas, mas apenas agora se vê a sua importância enquanto criador de valor, pois é através dele que se torna possível alcançar vantagens competitivas. Por conseguinte, os activos físicos e financeiros não permitem gerar vantagens competitivas sustentáveis no tempo, pelo que cabe aos activos de carácter intangível, aportar verdadeiro valor.

Serapicos (2002: 46) argumenta que o capital intelectual ajuda a explicar a diferença entre o valor de mercado e o valor dos livros das empresas, uma vez que o capital intelectual não se inclui nas contas financeiras da empresa. Refere que "Sendo o capital intelectual a principal fonte de riqueza das nossas empresas é totalmente lógico que a direcção das mesmas preste uma atenção especial à gestão eficaz do capital intelectual".

Com efeito e na mesma linha de pensamento, alega que a capacidade de identificar, auditar, renovar incrementar e gerir estes activos intelectuais representa actualmente um factor determinante para o êxito das empresas. Assiste-se por conseguinte, à realização de diversos esforços na procura de metodologias e modelos que concorram para melhorar a capacidade de gestão do capital intelectual, embora o êxito alcançado tenha sido relativo, em parte devido à própria natureza intangível destes activos.

Os activos intangíveis, não possuem as qualidades dos activos tangíveis, visto que na maioria não são concretos, não são sempre transferíveis, existe dificuldade na sua identificação e a sua avaliação económica é complexa, sendo por isso, difícil determinar em que medida influenciam o resultado da empresa (Navaza e Cabarcos 2007: 30-31).

Kaplan e Norton (1996), referidos por Russo (2006: 23) alvitram dois motivos para a dificuldade de medir os factores de sucesso intangíveis:

a. Os activos intangíveis actuam de forma indirecta sobre os resultados através de diversas relações de causa e efeito. Um exemplo é a formação de pessoal pela tendência na melhoria da qualidade dos serviços, o que implica um aumento de satisfação por parte dos clientes e, consequentemente, aumenta a fidelização dos mesmos. Geralmente, o aumento da fidelidade dos clientes leva ao aumento dos rendimentos e das margens da empresa. 
b. O valor dos activos intangíveis depende do contexto organizacional e da sua ligação com os outros activos e com a estratégia seguida.

Almeida (2003: 49), citando Warschat et al. (1999) enumeram, de forma resumida, as oportunidades e os riscos relacionados com a medição do capital intelectual, a saber:

\begin{tabular}{|c|c|}
\hline Oportunidades & Riscos \\
\hline Produtividade crescente & A partilha de conhecimento carece de treino \\
\hline Concorrência crescente & Ansiedade e falta de confiança dos empregados \\
\hline Utilização de potenciais de desenvolvimento & Exploração do trabalho \\
\hline Melhor planeamento estratégico & $\begin{array}{l}\text { Demasiado esforço associado ao desenvolvimento e } \\
\text { à implementação de um sistema de medição }\end{array}$ \\
\hline Eficácia e efectividade optimizadas & $\begin{array}{l}\text { Possível falta de objectividade em termos de escalas } \\
\text { de medida }\end{array}$ \\
\hline \multicolumn{2}{|l|}{ Melhor utilização dos recursos } \\
\hline Motivação para os empregados & \\
\hline
\end{tabular}

\subsection{Modelos de valoração dos activos intangíveis}

Para Almeida (2003: 40) os activos intangíveis possuem manifesto interesse económico face à sua crescente importância sobre os activos tangíveis na atribuição de valor de mercado às empresas, especificamente as de base tecnológica.

Em sua opinião, vários autores têm vindo a apresentar, e a procurar sistematizar, os métodos existentes para a medição (e a avaliação) dos activos intangíveis.

$\mathrm{Na}$ tentativa de mensuração dos activos intangíveis, onde se inclui o capital intelectual, têm surgido, nos últimos anos, uma série de propostas de métodos e teorias. Gama e Silva (2006) seguem a classificação de Sveiby (2005) e da Comissão Europeia (CEC 2003), em que sugerem pelo menos quatro categorias de metodologias de avaliação. Luthy (1998) e Williams (2000) são defensores da mesma classificação.

Segundo estes estudos, podem definir-se quatro tipos de métodos para quantificação dos activos intangíveis: 
- Direct Intellectual Capital Methods (DIC) - no qual se estima o valor monetário dos activos intangíveis através da identificação dos seus vários componentes, atribuindo valor monetário a cada um dos activos determinados. Este método não permite, contudo, a percepção global dos activos intangíveis da organização, nem valoriza as sinergias entre eles. Para contornar este problema é aplicado um coeficiente de agregação.

- Market Capitalization Methods (MCM) - Em que se calcula o valor dos activos intangíveis através da diferença entre o valor do mercado de capitais de uma companhia e os activos dos accionistas (stockholders' equity).

- Return on Assets Methods (RAM) - métodos que quantificam monetariamente o valor dos activos intangíveis pelos resultados obtidos divididos pelos activos tangíveis descontando os custos.

- Scorecard Methods (SC) - métodos não monetários que procuram identificar os vários componentes dos activos intangíveis, permitindo a criação de indicadores e índices reportados através de Balanced Scorecards. São os métodos mais usados para avaliar a saúde financeira das organizações. Apresentam o problema de, ao avaliarem a organização como um todo, surgir a dificuldade de determinar a contribuição parcelar do valor dos activos intangíveis.

Os métodos referidos apresentam vantagens diferentes. Os que contemplam avaliações financeiras (RAM e MCM) são de grande utilidade em processos de concentrações de actividades empresariais e nas avaliações de mercado. Podem também ser utilizados para comparações entre empresas do mesmo segmento, evidenciando o valor financeiro dos activos intangíveis como um todo. Apresentam ainda a vantagem de serem estabelecidos de acordo com regras contabilísticas, o que os torna populares junto dos CFO (Chief Financial Officers) ${ }^{2}$.

Possuem a desvantagem de apenas traduzirem o valor agregado total em termos monetários, o que pode não reflectir a dimensão real dos activos intangíveis.

Os métodos DIC e SC têm a vantagem de mostrar uma mais efectiva imagem da saúde da organização do que as métricas financeiras,

2 Pessoa que assume os riscos financeiros de um negócio. 
podendo ser aplicáveis a qualquer nível da organização. As medidas que preconizam estão mais próximas dos eventos e a transmissão de resultados pode ser mais rápida e precisa do que medidas financeiras globais puras. Por não quantificarem os activos intangíveis em termos financeiros, tornam-se muito atractivos junto das organizações sem fins lucrativos. Têm a desvantagem de conter indicadores muito contextuais e configurados para a organização em que são implementados, complicando desse modo a comparação. São métodos relativamente recentes, de aplicação não generalizada, que ainda são dificilmente aceites pelos administradores e analistas financeiros mais habituados a perspectivas financeiras (Sveiby 2005) (CEC 2003).

Gama e Silva (2006: 8) argumentam que se têm realizado outros trabalhos de investigação no sentido de modularem o valor intangivel dos sistemas de informação decorrente do alinhamento com recursos da organização assente em três factores-chave que conferem uma melhoria na performance: a estrutura, o capital humano e o seu relacionamento (Chaminade et al. 2000). Referem ainda que existem vários trabalhos de modulação matemática, em que se destaca a aplicação de modelos econométricos de derivação da valorização do mercado de acções baseado em normas da teoria financeira (Brynjolfsson et al. 2002).

Nenhum método, no entanto, pode atender a todos os propósitos e necessidades. Os interessados devem seleccionar o método que se lhes afigure mais recomendável conforme o fim em vista, a situação e o público interessado no trabalho (interno e externo).

Sveiby (1997b) considerou dois vectores de classificação: (i) existência, ou não, de avaliação financeira; (ii) análise apenas ao nível organizacional ou identificação de componentes. Para o autor, aparentemente, os métodos DIC juntariam o melhor dos dois mundos. No entanto, e considerando as evidências, não é demonstrado que estes métodos sejam preferidos em relação aos restantes na prática dos gestores do conhecimento (CKO - Chief Knowledge Officers). A maioria dos autores menciona frequentemente nas suas publicações mais recentes o Intangible Assets Monitor, de Karl-Erik Sveiby, e o Skandia Navigator" de Edvinsson e Malone, ambos métodos do tipo SC.

As razões subjacentes a esta tendência podem ter a ver com os seus aspectos mais positivos mencionados por Sveiby (2001), que poderão ser resumidos através de termos como abrangência, universalidade e adaptabilidade. Russo (2006: 81), neste entendimento refere que o 
Balanced Scorecard, conjuntamente com o Intangible Assets Monitor, e o Navigator, representam os três modelos mais significativos na medição do capital intelectual das organizações. Segundo Navaza e Cabarcos (2007: 31), o Balanced Scorecard "é mais do que um modelo que permite a avaliação de intangíveis, um sistema de gestão que leva em consideração tanto os medidores clássicos de uma empresa (os financeiros) como os medidores de capital intelectual".

\section{OS ACTIVOS INTANGÍVEIS NAS CONTAS DAS EMPRESAS DO}

PSI 20

Neste ponto, vamos apresentar os dados resultantes duma pesquisa efectuada nas contas consolidadas de algumas empresas ${ }^{3}$ que compõem o PSI 20 , segundo a qual é possível verificar que estas integram elementos intangíveis conforme consta do quadro seguinte:

Quadro 1: Activos intangíveis

\begin{tabular}{|c|c|c|c|c|}
\hline & & & & $M €$ \\
\hline & & $\begin{array}{c}\text { CONTAS } \\
\text { @NSOUDADAS }\end{array}$ & & \\
\hline SOAEDADE & & ANO 2007 & & ANO 2006 \\
\hline & GOODWIU & $\begin{array}{c}\text { IMOB. } \\
\text { INOORPÓREO/ } \\
\text { ACT. INTANGÍVES }\end{array}$ & GOODWIL & $\begin{array}{c}\text { IMOB. } \\
\text { INOORPÓREO / } \\
\text { ACT. INTANGÍVES }\end{array}$ \\
\hline ALTRI & & $967.621,00$ & & $667.898,00$ \\
\hline BPI & & $15.453,00$ & & $8.803,00$ \\
\hline BRISA & $29.436,00$ & $866.692,00$ & $31.630,00$ & $379.966,00$ \\
\hline AMPOR & $1.283 .741,00$ & $13.302,00$ & $909.971,00$ & $10.720,00$ \\
\hline EDP & & $5.222,00$ & & $3.639,00$ \\
\hline GALP & $17.222,00$ & $309.502,00$ & $17.032,00$ & $324.767,00$ \\
\hline JERÓNIMO MARTINS & $416.290,00$ & $496.293,00$ & $385.341,00$ & $446.385,00$ \\
\hline MOTA 日NGIL & $157.753 .345,00$ & $46.971 .911,00$ & $56.935 .679,00$ & $3.516 .578,00$ \\
\hline PORTUCE & $376.756 .384,00$ & $1.419 .321,00$ & $376.756 .384,00$ & $2.205 .057,00$ \\
\hline PORTUGAL TEEEOM & & $3.383,10$ & & $3.490,90$ \\
\hline SONAE SGPS & 740,90 & $347.668 .144,00$ & 250,80 & $321.517 .485,00$ \\
\hline ZON MULTIMÉIA & & $259.672 .450,00$ & & $283.615 .597,00$ \\
\hline
\end{tabular}

3 À data de elaboração deste artigo, apenas estavam disponíveis as contas consolidadas de 2007 das empresas que integram o índice PSI 20, constantes do quadro. 
Dos activos intangíveis reconhecidos, constam elementos tais como se indicam no quadro que se segue:

Quadro 2: Activos intangíveis - elementos

\begin{tabular}{|c|c|c|c|c|c|c|c|c|c|c|}
\hline \multicolumn{11}{|c|}{ contas consolidadas 2007} \\
\hline & $\mid \begin{array}{c}\text { goodwil } \\
1\end{array}$ & $\begin{array}{c}\text { despesas } \\
\text { de i\&d }\end{array}$ & $\begin{array}{c}\text { Software } \\
\text { e Prop. } \\
\text { Ind. E } \\
\text { Outros } \\
\text { Direitos }\end{array}$ & $\begin{array}{c}\text { Trespas } \\
\text { ses }\end{array}$ & \begin{tabular}{|c} 
Activos \\
intangí \\
veis em \\
curso
\end{tabular} & \begin{tabular}{|c|} 
aquisição \\
de \\
subsidiári \\
as ou \\
empresas \\
conjunta \\
mente \\
controlad \\
as
\end{tabular} & \begin{tabular}{|c} 
licenças \\
de \\
exploraç \\
ão e \\
concessõ \\
es
\end{tabular} & $\begin{array}{c}\text { imobiliz } \\
\text { ações } \\
\text { em } \\
\text { curso }\end{array}$ & $\begin{array}{l}\text { outras } \\
\text { imob } \\
\text { incorp }\end{array}$ & marcas \\
\hline ALTRI & & $\mathrm{x}$ & $\mathrm{x}$ & & & & & & & \\
\hline BP & & & $\mathrm{x}$ & & $\mathrm{x}$ & & & & $\mathrm{x}$ & \\
\hline BRISA & $\mathrm{x}$ & & & & & $\mathrm{x}$ & & & $\mathrm{x}$ & \\
\hline AMPOR & $\mathrm{x}$ & $\mathrm{x}$ & $\mathrm{x}$ & & $\mathrm{x}$ & & & & & \\
\hline$E \mathrm{DP}$ & & & & & & $\mathrm{x}$ & & & & \\
\hline GALP & $\mathrm{x}$ & $\mathrm{x}$ & & & & $\mathrm{x}$ & & & & \\
\hline JRÓNIMO MARTINS & $\mathrm{x}$ & $\mathrm{x}$ & $\mathrm{x}$ & $\mathrm{x}$ & $\mathrm{x}$ & & & & & \\
\hline MOTA ENGIL & $\mathrm{x}$ & $\mathrm{x}$ & $\mathrm{x}$ & & & $x$ & $x$ & $\mathrm{x}$ & $\mathrm{x}$ & \\
\hline PORTUCE & $\mathrm{x}$ & $\mathrm{x}$ & $\mathrm{x}$ & & & $\mathrm{x}$ & & $\mathrm{x}$ & & $\mathrm{x}$ \\
\hline \multicolumn{2}{|l|}{ PORTUGAL TEECOM } & & $x$ & & & $x$ & & & $x$ & $x$ \\
\hline SONAESGPS & $\mathrm{x}$ & & $x$ & & & $\mathrm{x}$ & & $x$ & $x$ & $\mathrm{x}$ \\
\hline ZON MULTIMÉDIA & $\mathrm{x}$ & & $x$ & & & $\mathrm{x}$ & & & $x$ & $\mathrm{x}$ \\
\hline
\end{tabular}

Graficamente, temos:

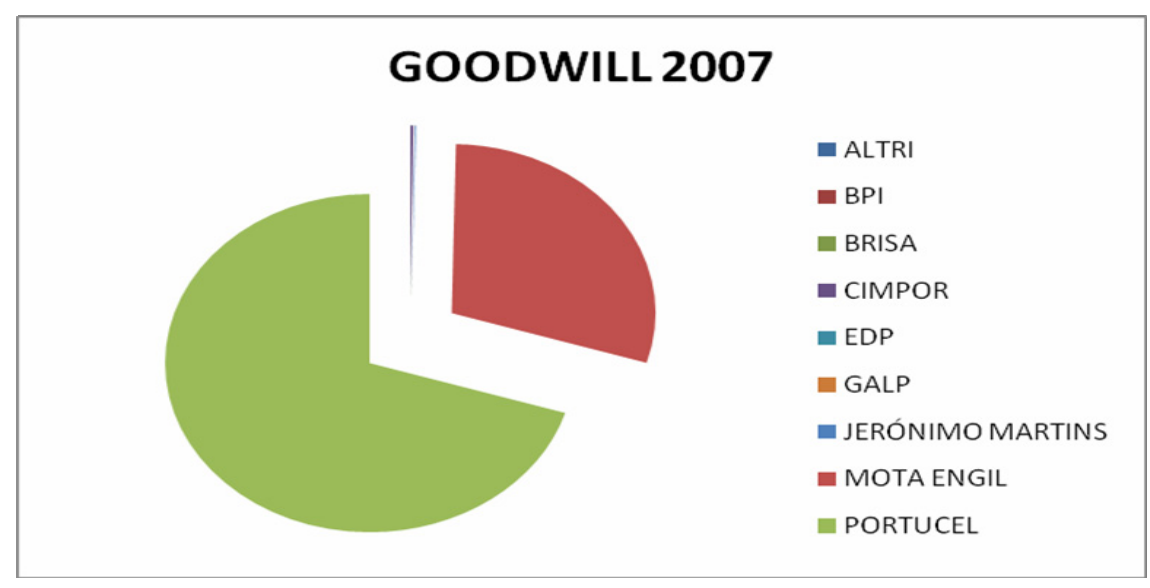




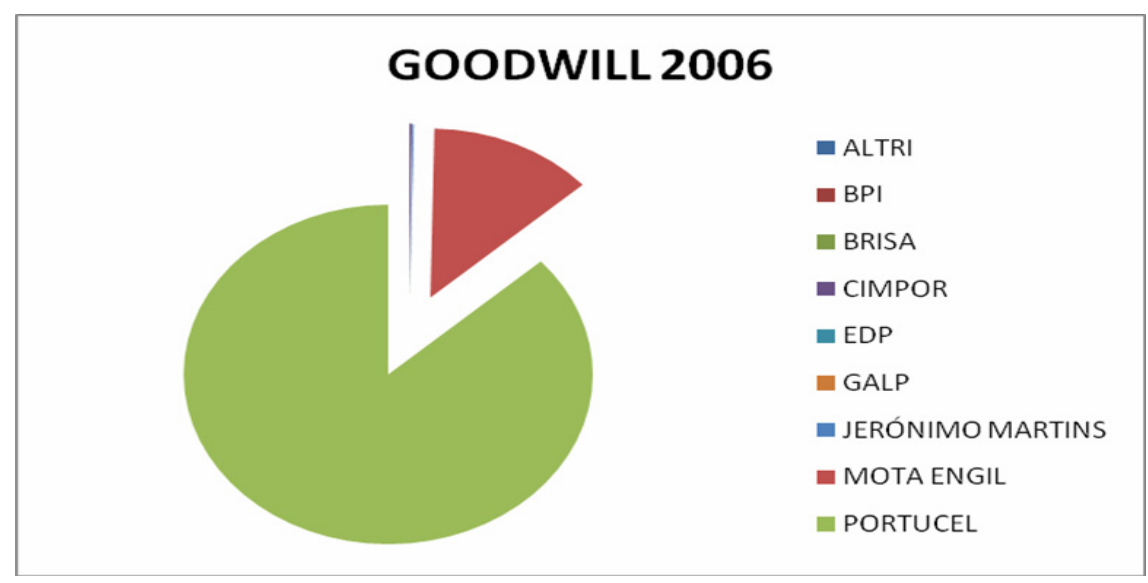

IMOB. INCORPÓREO / ACT. INTANGÍVEIS 2007

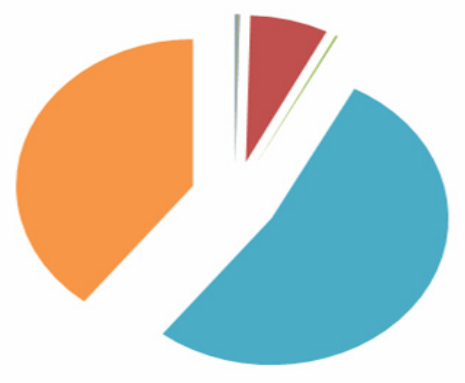

$=$ ALTRI
$=$ BPI
$=$ BRISA
$=$ CIMPOR
$=$ EDP
$=$ GALP
$\square$ JERÓNIMO MARTINS
$\square$ MOTA ENGIL

IMOB. INCORPÓREO / ACT. INTANGÍVEIS 2006

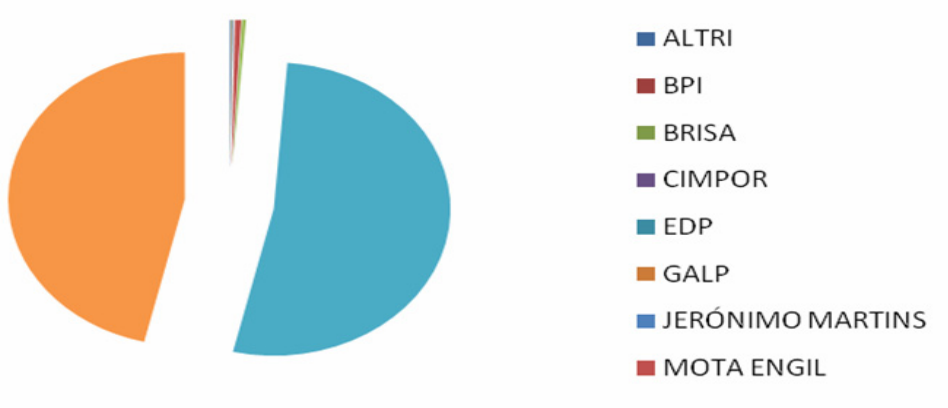

Pecvnia, 8 (2009), pp. 183-201 
Conforme se pode verificar, os valores correspondentes à maioria das empresas sofreram um crescimento em 2007, o que denota que os activos intangíveis têm vindo a representar, cada vez mais, uma parte importante dos recursos das empresas.

\section{CONCLUSÕES}

Actualmente, os activos intangíveis são um factor determinante para o êxito das empresas. Na era da informação, a gestão das empresas não se pode basear em antigos sistemas de medição, tendo por isso, nos últimos anos, sido realizados numerosos esforços na procura de metodologias e modelos que contribuam para melhorar a capacidade de gestão do capital intelectual.

A medição dos activos intangíveis é uma área onde a desproporção é muito ampla. As alternativas ao custo histórico, baseadas em modelos de propriedade ou em modelos certificados, são insuficientes porque exigem julgamentos que conduzem a variações substanciais. É por isso necessário uma discussão mais profunda e a necessária investigação, para que os activos intangíveis se possam valorizar adequadamente, e, assim, calcular o valor financeiro que lhe é atribuído.

As organizações com elevado nível de investimento em capital intelectual têm um valor agregado muito superior às organizações com investimentos baseados noutro tipo de activos. Tal valor, embora incorporado nas cotações de mercado, não encontra expressão nas tradicionais demonstrações financeiras, pelo que não é possível determinar o real valor dos activos intangíveis nas organizações.

As contas consolidadas das empresas que compõem o PSI 20, em análise, evidenciam nos anos de 2006 e 2007, na sua maioria, incrementos nos activos intangíveis. Não existe no entanto um carácter de uniformidade relativamente ao tipo de intangíveis que cada empresa reconhece, pelo que estudos posteriores terão de ser efectuados para se analisar a tendência e o comportamento das empresas neste âmbito. 


\section{BIBLIOGRAFIA}

ALMEIDA, Pedro J.M. (2003) Da capacidade empreendedora aos activos intangíveis no processo de criação de empresas do conhecimento. Universidade Técnica de Lisboa, IST. Tese de mestrado em Eng $^{\text {a }}$ e Gestão de Tecnologia. [http://purl.pt/6547. Consult. 29 Mai. 2007].

BROOKING, A. (1996) Intellectual Capital. Core Asset for the Third Millennium Enterprise. London: International Thomson Business Press.

Bueno Campos, E. y C. Merino MOReno (2007) "El capital intelectual y la creación de empresas en la sociedad del conocimiento", Encuentros multidisciplinares, 9, $\mathrm{n}^{\circ}$ 26, pp. 37-46.

EDVINSSON, L. y M.S. MALONE (1999) El Capital Intelectual - Como identificar y calcular el valor de los recursos intangibles de su empresa. Barcelona: Ediciones Gestión 2000, S.A.

EUROFORUM (1998) Proyecto Intelect. Medición del Capital Intelectual. Madrid: Euroforum.

Gama, N.P. da e M.M. da SiLva (2006) Activos intangíveis dos sistemas de informação [www.col.tagus.ist.utl.pt. Junho 2008].

GUTIÉRREZ, F.R. (2004) Medición y valoración de activos intangibles en los estados financieros. Caso: empresas de la industria biotécnica. [www.monografias.com. Maio 2008].

INTERNATIONAL ACCOUNTING STANDARDS BOARD (IASB) (2004) "Estrutura Conceptual para a Apresentação e Preparação de Demonstrações Financeiras". OROC e IASB (eds.) Normas Internacionais de Relato Financeiro (IFRSSTM) incluindo as Normas Internacionais de Contabilidade (IASsTM), pp.19-46.

- (2004) "Norma Internacional de Contabilidade (IAS) n. 38 - Activos Intangíveis". OROC e IASB (eds.) Normas Internacionais de Relato Financeiro (IFRSsTM) incluindo as Normas Internacionais de Contabilidade (IASsTM), pp.1.187-1.228.

KAPLAN, R. y D. NORTON (1996) "Strategic Learning and the Balanced Scorecard", Strategy and Leadership, September/October, pp. 18-24.

KAPLAN R.S. \& D.P. NORTON (1996) The Balanced Scorecard: Translating Strategy into Action. Harvard Business School Press.

LEV, B. (2000) Knowledge and Shareholder Value: Working Paper. Stern School of Business, New York University.

LUTHY, D.H. (1998) Intellectual Capital and Its Measurement [http://www 3.bus.osakacu]. 
MARQUES, Maria da Conceição da Costa (2005) "O capital intelectual no sector público". Comunicação apresentada nas XV Jornadas HispanoLusas de Gestão Científica, Sevilha. Acessível no Instituto Superior de Contabilidade e Administração de Coimbra. Coimbra. Portugal.

NAvazA, Calos L.; M.A.L. Cabarcos (2007) Empresas Valiosas - Do Capital Intelectual à Criação de Valor. Porto: Vida Económica.

PuCICH, M.; E.C. MONZÓN y L. SOSISKY (2001) "Los Recursos Intangibles en la Información Contable", XVI Jornadas de Contabilidad, XIV de Auditoria y III de Gestión y Costos. Colegio de Graduados en Ciencias Económicas de la Capital Federal. Buenos Aires, Argentina.

Russo, João (2006) Balanced Scorecard para PME. Lisboa: Lidel.

SERAPICOS, Elizabete (2003) "A importância estratégica da gestão do conhecimento", Revista TOC, 38, pp. 56-57.

SERRANO CinCA, C. y F. ChaPARRo (2001) Los activos intangibles en la Contabilidad: medición y valoración. [http://www.5campus.com/ leccion/capint1. Consult. 10/12/2002].

STEWART, T.A. (1998) Capital Intelectual: a nova riqueza das organizações. Lisboa: Edições Sílabo.

SVEIBY, K.E. (1997a) The Invisible Balance Sheet: Key Indicators for Accounting, Control And Evaluation Of Know-How Companies. Stockholm: The Konrad Group.

SVEIBY, K. (1997b) The New Organizational Wealth: Managing and Measuring Knowledge Based Assets. San Francisco, CA: Berrett Koehler.

- (1997c) "The Intangible Assets Monitor", Journal of Human Resource Costing and Accounting, 2 (1), pp. 73-97.

- (2001) What is Knowledge Management? [http://www.sveiby.com/arti cles/knowledge_management_articles.html].

- (2005) Methods for Measuring Intangible Assets [http://www.sveiby.co $\mathrm{m} /$ articles/IntangibleMethods.htm. Dezembro 2005]. 